\title{
Case for diagnosis
}

\author{
Caso para diagnóstico
}

Ludmilla Queirós Miranda ${ }^{1}$

Roberto Souto da Silva ${ }^{3}$

Maria de Fátima Guimarães Scotelaro Alves ${ }^{5}$

\section{CASE REPORT}

Healthy 30 year old male patient reported presence since 3 years previously of normochromic nodule of firm consistency, painful on palpation, $4 \mathrm{~cm}$ in diameter, located on the palm side of the middle phalanx of the $2^{\text {nd }}$ finger of the left hand (Figures 1 and 2). Patient denied previous trauma at the site. Xrays of the left hand and a soft tissue USG revealed no

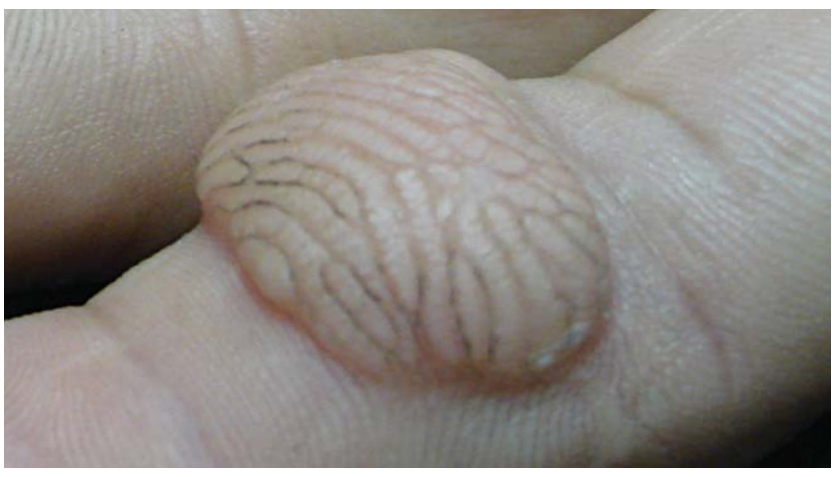

Figure 1: Normochromic nodule on the palm side of the second finger of the left hand

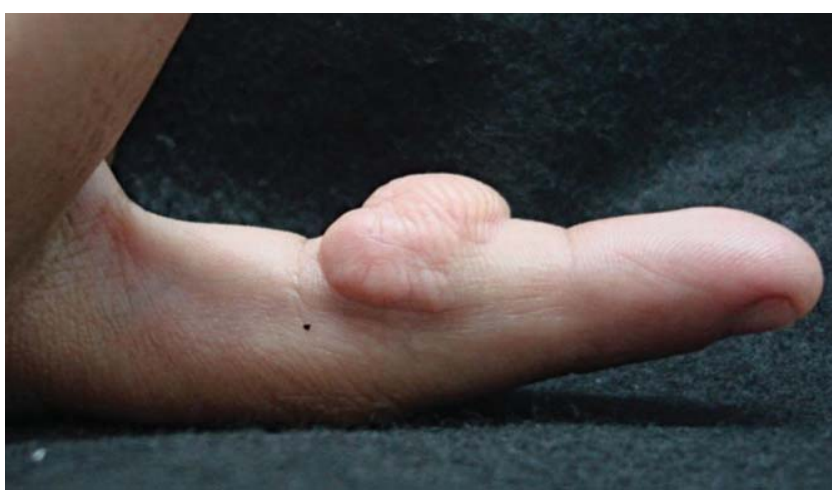

Figure 2: Side view of the nodule

\author{
Fernanda Valente da Silva Rehfeldt ${ }^{2}$ \\ João Carlos Macedo Fonseca ${ }^{4}$
}

changes. We performed an excisional biopsy of the lesion and the histopathological examination revealed hyperkeratosis with acanthosis, and multiple bundles of muscle fibers in the dermis, arranged in several directions and interspersed with blood vessels of different sizes (Figure 3). Staining with Masson's trichrome was positive for smooth muscle actin (Figure 4).

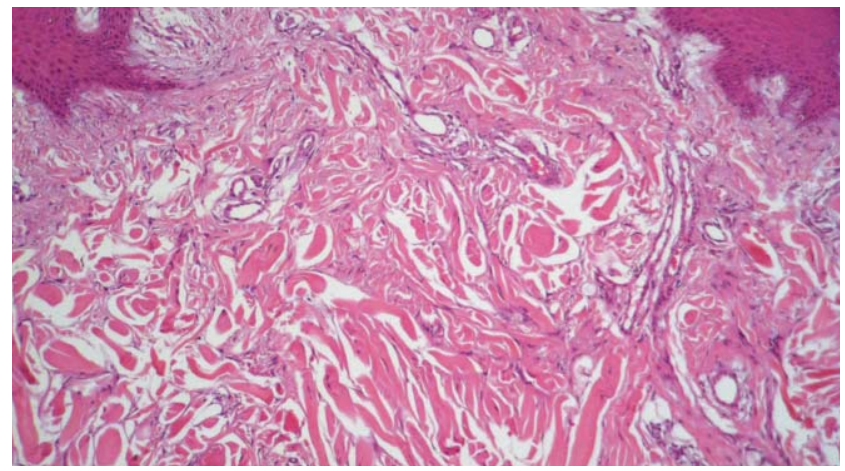

Figure 3: Histopathology reveals bundles of muscle fibers interspersed with vessels of different sizes

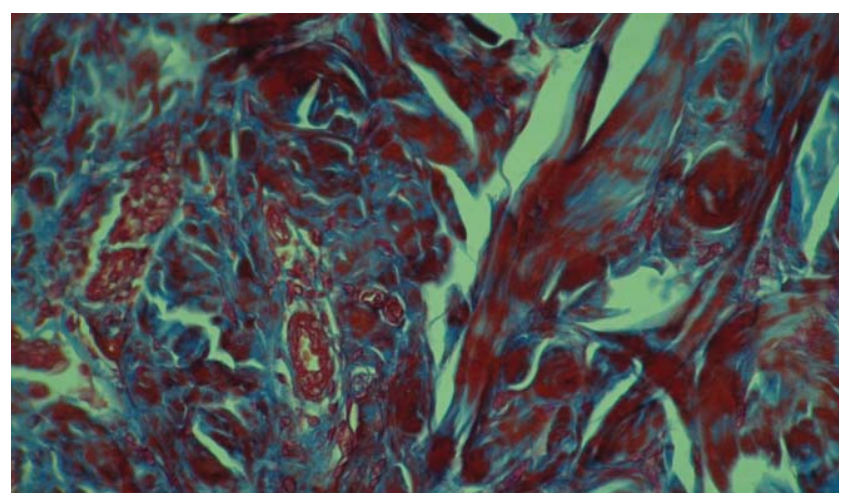

Figure 4: Masson's Trichrome staining

Received on 21.03.2011.

Approved by the Advisory Board and accepted for publication on 01.05.2011.

* Work done at the Department of Dermatology, Pedro Ernesto University Hospital, Universidade do Estado do Rio de Janeiro (HUPE-UERJ), Rio de Janeiro (RJ), Brazil. Conflict of interest: None / Conflito de interesse: Nenbum

Financial funding: None / Suporte financeiro: Nenhum

\footnotetext{
Postgraduate student in Dermatology, Pedro Ernesto University Hospital, Universidade do Estado do Rio de Janeiro (HUPE-UERJ), Rio de Janeiro (RJ), Brazil. Resident in Dermatology at Pedro Ernesto University Hospital, Universidade do Estado do Rio de Janeiro (HUPE-UERJ), Rio de Janeiro (RJ), Brazil.

Master in Dermatology and Preceptor of the Department of Dermatology, Pedro Ernesto University Hospital, Universidade do Estado do Rio de Janeiro (HUPE-UERJ), Rio de Janeiro (RJ), Brazil.

Doctor in Dermatology. Associate Professor of Dermatology, Pedro Ernesto University Hospital, Universidade do Estado do Rio de Janeiro (HUPE-UERJ), Rio de Janeiro (RJ), Brazil.

Doctor in Dermatology. Associate Professor of Dermatology and in charge of the Dermatopathology Sector at the Pedro Ernesto University Hospital, Universidade do Estado do Rio de Janeiro (HUPE-UERJ), Rio de Janeiro (RJ), Brazil.
} 


\section{DISCUSSION}

Leiomyomas are uncommon benign smooth muscle tumors, divided according to their origin into 3 different types: piloleiomyomas, angioleiomyomas and genital leiomyomas. The piloleiomyomas are the most frequent, originating from the arrector pili muscle, whereas angioleiomyomas arise from the vascular smooth muscle and genital leiomyomas from the smooth muscle of the vulva, scrotum and nipples.

Although most leiomyomas are acquired, reports exist of hereditary forms of autosomal dominant transmission and variable penetrance. ${ }^{1}$ The literature suggests some etiologic factors for angioleiomyomas, such as hormonal changes (principally associated with estrogen), previous trauma and venous stasis. ${ }^{2}$

Angioleiomiomas usually occur in women aged between 40 and 60, and present as painful solitary nodules of up to $2 \mathrm{~cm}$ in diameter, located on the extremities (especially the lower limbs). Some reports suggest that angioleiomyomas in the upper limbs are more frequent in men, while the lower limb lesions tend to affect women more. ${ }^{3.4}$ Lesions in the upper limbs are mainly located in the dorsal and palmar aspect of the hand, wrist and forearms. Angioleiomyomas 4 located in the fingers are rare. ${ }^{5}$

Angioleiomyomas are characterized histologically by the proliferation of smooth muscle bundles with spindleshaped nuclei, blunt ends and eosinophilic cytoplasm, intermingled with vessels of different size. Three histological types exist: solid, in which the muscle bundles are interspersed with small vascular channels; cavernous, in which there is dilatation of the vascular channels and the vessel walls can be barely distinguished from the intervascular smooth mus- cle; and the venous type, characterized by thick-walled blood vessels and less compact muscle bundles. ${ }^{3.6}$ Special stains such as Masson's trichrome can be used to differentiate smooth muscle from collagen. Immunohistochemistry is positive for desmin and actin.

Leiomyoma is a rare tumor of the hand, and its diagnosis should be suspected in patients with a solitary painful slow-growing nodule. The pain may be spontaneous or induced by cold, touch, pressure and stress. ${ }^{7}$ The most credible theories proposed to explain the pathophysiology of pain in these tumors suggest that the local ischemia is caused by the tumor`s muscle fibers contracting and making contact with the peripheral nerve fibers. ${ }^{3}$

In the differential diagnosis a number of painful skin tumors should be considered. These include leiomyosarcoma, angiolipoma, glomus tumor, eccrine espiradenoma and neurofibroma. The histologic differentials are smooth muscle hamartoma and dermatofibroma.

The therapeutic approach depends on the size of the lesion and the severity of symptoms. Surgical excision is the treatment of choice for solitary leiomyomas. Drug treatment with nifedipine, gabapentin and antidepressants can be undertaken in cases where tumors are both numerous and painful. ${ }^{8}$

This case illustrates an uncommon type of tumor (also located in an uncommon place) which was diagnosed only after excision and histopathologic examination. Regardless of the fact that angioleiomiomas are classically benign, reports do exist of bone destruction. It is therefore important always to suspect this when presented with a slow-growing solitary nodular lesion located on the extremities. ${ }^{9} \square$

\begin{abstract}
Vascular leiomyoma are uncommon benign smooth muscle tumors which generally present as a single painful nodule in the lower limbs. We report a case of vascular leiomyoma on the second finger of the left hand, an unusual location for this tumor.

Keywords: Blood vessels; Hands; Leiomyoma; Smooth muscle tumor

Resuimo: Angioleiomiomas são tumores benignos raros derivados da musculatura lisa vascular, que geralmente se apresentam como nódulo doloroso solitário nos membros inferiores. Relata-se um caso de angioleiomioma no segundo quirodátilo esquerdo, localização incomum deste tumor.

Palavras-chave: Leiomioma; Mãos; Tumor de músculo liso; Vasos sanguíneos
\end{abstract}

\section{REFERENCES}

1. Fernández-Pugnaire MA, Delgado-Florencio V. Familial multiple cutaneous leiomyomas. Dermatology. 1995;191:295.

2. Hasey TC, Hosey TC, Jacob T, Kaller H. Vascular leiomyoma. A case report and review of the literature. J Am Podiatr Assoc. 1984;74:93-5.

3. Lawson GM, Salter DM, Hooper G. Angioleiomyomas of the hand: a report of 14 cases. J Hand Surg Br. 1995;20:479-83.

4. Herren DB, Zimmermann A, Buchler U. Vascular leiomyoma in an index finger undergoing malignant transformation. J Hand Surg Br. 1995;20:484-7.

5. Uchida M, Kojima T, Hirase Y, lizuka T. Clinical characteristics of vascular leiomyoma of the upper extremity: report of 11 cases. Br J Plast Surg. 1992;45:547-9.

6. Hachisuga T, Hashimoto H, Enjoji M. Angioleiomyoma: a clinicopathologic reappraisal of 562 cases. Cancer. 1984;54:126-30.

7. Hoslt VA, Junkins-Hopkins JM, Elenitsas R. Cutaneous smooth muscles neoplasms: clinical features, histologic findings, and treatment options. J Am Acad Dermatol. 2002;46:477-90.
8. Suzuki HS, Cavalin LC, Werner B, Sato MS, Brenner FM. Caso para diagnóstico. Piloleiomioma multiplo. An Bras Dermatol. 2007;82:190-2.

9. Glowacki K, Weiss A. Vascular leiomyoma of the finger causing bone erosion. J Hand Surg Am. 1995;20:1011-3.
MAILING ADDRESS:
Ludmilla Queirós Miranda
Avenida 28 de setembro, 77 - Vila Isabel
20551-030 Rio de Janeiro (RJ), Brazil
E-mail:ludqmiranda@botmail.com

How to cite this article: Miranda LQ, Rehfeldt FVS, Silva RS, Fonseca JCM, Alves MFGS. Case for diagnosis. Vascular leiomyoma in the finger. An Bras Dermatol. 2012;87(2):322-3. 